\title{
Forecasting Wind Speed in Peninsular Malaysia: An Application of ARIMA and ARIMA-GARCH Models
}

\author{
Nor Hafizah Hussin 1,2*, Fadhilah Yusof', 'Aaishah Radziah Jamaludin² and Siti \\ Mariam Norrulashikin ${ }^{2}$
}

${ }^{1}$ Faculty of Electrical and Electronic Engineering Technology, Universiti Teknikal Malaysia Melaka, Hang Tuah Jaya, 76100, Durian Tunggal, Melaka, Malaysia

${ }^{2}$ Department of Mathematical Sciences, Faculty of Science, Universiti Teknologi Malaysia, 81300, Johor Bahru, Johor, Malaysia

\begin{abstract}
In the global energy context, renewable energy sources such as wind is considered as a credible candidate for meeting new energy demands and partly substituting fossil fuels. Modelling and forecasting wind speed are noteworthy to predict the potential location for wind power generation. An accurate forecasting of wind speed will improve the value of renewable energy by enhancing the reliability of this natural resource. In this paper, the wind speed data from year 1990 to 2014 in 18 meteorological stations throughout Peninsular Malaysia were modelled using the Autoregressive Integrated Moving Average (ARIMA) to forecast future wind speed series. The Ljung-Box test was used to determine the presence of serial autocorrelation, while the Engle's Lagrange Multiplier (LM) test was used to investigate the presence of Autoregressive Conditional Heteroscedasticity (ARCH) effect in the residual of the ARIMA model.

ARTICLE INFO

Article history:

Received: 6 July 2020

Accepted: 5 November 2020

Published: 22 January 2021

DOI: https://doi.org/10.47836/pjst.29.1.02

E-mail addresses:

norhafizah.hussin@graduate.utm.my (Nor Hafizah Hussin) fadhilahy@utm.my (Fadhilah Yusof)

aishahjamaludin85@gmail.com ('Aaishah Radziah Jamaludin)

sitimariam@utm.my (Siti Mariam Norrulashikin)

*Corresponding author

In this study, three stations showed good fit using the ARIMA modelling since no serial correlation and $\mathrm{ARCH}$ effect were present in the residuals of the ARIMA model, while the ARIMA-GARCH had proven to precisely capture the nonlinear characteristic of the wind speed daily series for the remaining stations. The forecasting accuracy measure used was based on the value of root mean square error (RMSE) and mean absolute percentage error (MAPE). Both ARIMA and
\end{abstract}


ARIMA-GARCH model proposed provided good forecast accuracy measure of wind speed series in Peninsular Malaysia. These results will help in providing a quantitative measure of wind energy available in the potential location for renewable energy conversion.

Keyword: Forecasting, modelling, renewable energy, time series method, wind speed

\section{INTRODUCTION}

In this rapid population growth, the energy demand has increased to support human consumption. The negative effect is energy usage has increased the demand on energy resulting in depletion of natural resources and will cause a harmful effect towards the environment (Ajayi et al., 2014). To overcome this issue, many developed countries are now focusing on conserving the non-renewable energy by switching to renewable energy sources like wind and solar. Wind power is one of the natural sources of renewable energy that is experiencing the fastest growth is the wind energy. Unlike solar energy, wind power can provide energy throughout day and night since it does not require any sunlight (Petinrin \& Shaaban, 2015).

Many researchers have studied wind speed modelling and forecasting using various models which were developed in improving the wind speed forecasting accuracy (Chang et al., 2016; De Freitas et al., 2018; Norrulashikin et al., 2018; Sharma \& Singh, 2018). According to Erdem et al. (2014), there are two main aspects to be considered in building a wind speed prediction model which is to predict the mean wind speed and the wind speed volatility. Commonly used models include autoregressive (AR) model, moving average (MA) model (Akcan, 2017), autoregressive moving average (ARMA) model (Lujano-Rojas et al., 2011), and autoregressive integrated moving average (ARIMA) model (Radziukynas $\&$ Klementavicius, 2014). These models assume that the occurrence of turbulence in the wind speed is constant or in other words, homoscedastic. However, wind speed series can exhibit the characteristics of nonlinear variance where it is often referred to as volatility and may vary over time. Therefore, the presence of nonlinear variance in a model needs to be investigated before any prediction is performed. If the error estimation for this variation of wind speed is underestimated, the prediction model might fail to provide accurate wind speed forecasting that will cause serious problems in the operation of wind turbine (Engle, 2001).

Hence, this study was conducted to propose a forecasting model using the ARIMA model. The proposed model with the presence of serial autocorrelation and effect of heteroscedasticity in the residual part of the series would be treated using the Generalized Autoregressive Conditional Heteroskedastic (GARCH) model. A related study by Masseran (2016) used an ARIMA-ARCH model to investigate the effect of mean and volatility of 
the wind speed. Yan et al. (2016) suggested the ARIMA-GARCH model for forecasting a short-term wind speed series. The proposed model had successfully managed to capture the heteroscedasticity of wind speed series and gave a higher prediction accuracy compared to the ARIMA model. Based on Lojowska et al. (2010), the advantage of modelling using ARMA-GARCH model is that it has the capability to handle the dominant criteria of the data series, which is distribution, time dependence structure as well as periodicity. For the purpose of wind speed forecasting, Grigonyte \& Butkevičiūtè (2016) used the ARIMA model to forecast a short-term wind speed in Latvia and the forecasting accuracy for the proposed model was based on root mean square error (RMSE) and mean absolute percentage error (MAPE) and mean absolute error (MAE) which allowed to establish an optimal model structure. While Sharma and Ghosh (2016) used MAPE in measuring the short-term wind speed forecasting in India and the finding suggested that ARIMA-GARCH model yielded smallest value of MAPE compared to other proposed models.

The aim of this study was to develop a time series model of daily wind speed series in Peninsular Malaysia. Box-Jenkins ARIMA model was used to model the series of each 18 stations and 15 stations were found to have a serial correlation and heteroscedastic effect in the residuals of the proposed model. Therefore, an ARIMA-GARCH model that is proven to help in capturing the serial autocorrelation and the heteroscedastic effects of a time series process was used. This hybrid model would help to overcome the linear limitation of ARIMA model for the purpose of obtaining a time series model that yielded higher accuracy of forecasting results.

\section{MATERIALS AND METHODS}

This research used a daily wind speed series collected from Malaysian Meteorological Department (MMD) which consisted of data from 1990 to 2014. Data of daily wind speed series from 18 meteorological stations throughout the Peninsular Malaysia were chosen for this study from different regions. The last 365 days of daily wind speed data for each station would be considered as the out-sample data which will be compared with the forecasted daily wind speed series based on the best fitted model. In this study, time series analysis was applied due to the ability to interpret the presence of internal structure that might occur to the data point taken over time. For instance, the condition of serial autocorrelation and heteroscedastic effects should be taken into account in the analysis.

\section{Data Description}

The daily wind speed data from 18 different locations in Peninsular Malaysia with a duration from 1/1/1990 to 31/12/2014 were used in this study. The location in Peninsular Malaysia were divided into 4 regions, namely: northern, east coast, central, and southern. The northern region consists of stations that are located in Perlis, Kedah, Pulau Pinang 
and Perak, while the east coast region consists of stations that are located in the state of Kelantan, Terengganu, and Pahang. The central region consists of stations that are located in Selangor, Kuala Lumpur, and Putrajaya, and the southern region consists of stations that are located in Negeri Sembilan, Melaka, and Johor. The detailed information on the stations used in this study are given in Table 1 while Figure 1 shows the location of the stations on the map of Peninsular Malaysia.

Table 1

Coordinates for 18 stations used for wind speed data collection in Peninsular Malaysia

\begin{tabular}{llll}
\hline Location & Station & Latitude & Longitude \\
\hline Chuping & NS1 & $6^{\circ} 28^{\prime} 47.0^{\prime \prime} \mathrm{N}$ & $100^{\circ} 15^{\prime} 36.1^{\prime \prime} \mathrm{E}$ \\
Langkawi & NS2 & $6^{\circ} 20^{\prime} 13.0^{\prime \prime} \mathrm{N}$ & $99^{\circ} 43^{\prime} 35.4^{\prime \prime} \mathrm{E}$ \\
Bayan Lepas & NS3 & $5^{\circ} 17^{\prime} 43.4^{\prime \prime} \mathrm{N}$ & $100^{\circ} 16^{\prime} 06.6^{\prime \prime} \mathrm{E}$ \\
Butterworth & NS4 & $5^{\circ} 27^{\prime} 53.9^{\prime \prime} \mathrm{N}$ & $100^{\circ} 22^{\prime} 59.2^{\prime \prime} \mathrm{E}$ \\
Lubok Merbau & NS5 & $4^{\circ} 47^{\prime} 42.9^{\prime \prime} \mathrm{N}$ & $100^{\circ} 53^{\prime} 46.6^{\prime \prime} \mathrm{E}$ \\
Sitiawan & NS6 & $4^{\circ} 13^{\prime} 17.1^{\prime \prime} \mathrm{N}$ & $100^{\circ} 42^{\prime} 05.5^{\prime \prime} \mathrm{E}$ \\
Kota Bharu & $\mathrm{ES} 7$ & $6^{\circ} 09^{\prime} 12.6^{\prime \prime} \mathrm{N}$ & $102^{\circ} 18^{\prime} 41.0^{\prime \prime} \mathrm{E}$ \\
Kuala Terengganu & $\mathrm{ES} 8$ & $5^{\circ} 22^{\prime} 59.3^{\prime \prime} \mathrm{N}$ & $103^{\circ} 06^{\prime} 28.8^{\prime \prime} \mathrm{E}$ \\
Cameron Highland & $\mathrm{ES} 9$ & $4^{\circ} 29^{\prime} 04.0^{\prime \prime} \mathrm{N}$ & $101^{\circ} 22^{\prime} 17.4^{\prime \prime} \mathrm{E}$ \\
Kuantan & $\mathrm{ES} 10$ & $3^{\circ} 46^{\prime} 22.9^{\prime \prime} \mathrm{N}$ & $103^{\circ} 12^{\prime} 42.3^{\prime \prime} \mathrm{E}$ \\
Subang & $\mathrm{CS} 11$ & $3^{\circ} 07^{\prime} 52.0^{\prime \prime} \mathrm{N}$ & $101^{\circ} 33^{\prime} 09.8^{\prime \prime} \mathrm{E}$ \\
Petaling Jaya & $\mathrm{CS} 12$ & $3^{\circ} 06^{\prime} 26.0^{\prime \prime} \mathrm{N}$ & $101^{\circ} 38^{\prime} 52.9^{\prime \prime} \mathrm{E}$ \\
Sepang & $\mathrm{CS} 13$ & $2^{\circ} 43^{\prime} 54.2^{\prime \prime} \mathrm{N}$ & $101^{\circ} 42^{\prime} 10.5^{\prime \prime} \mathrm{E}$ \\
Melaka & $\mathrm{SS} 14$ & $2^{\circ} 15^{\prime} 17.2^{\prime \prime} \mathrm{N}$ & $102^{\circ} 14^{\prime} 36.0^{\prime \prime} \mathrm{E}$ \\
Mersing & $\mathrm{SS} 15$ & $2^{\circ} 26^{\prime} 42.6^{\prime \prime} \mathrm{N}$ & $103^{\circ} 49^{\prime} 52.6^{\prime \prime} \mathrm{E}$ \\
Batu Pahat & $\mathrm{SS} 16$ & $1^{\circ} 52^{\prime} 14.5^{\prime \prime} \mathrm{N}$ & $102^{\circ} 59^{\prime} 25.6^{\prime \prime} \mathrm{E}$ \\
Kluang & $\mathrm{SS} 17$ & $2^{\circ} 01^{\prime} 41.6^{\prime \prime} \mathrm{N}$ & $103^{\circ} 19^{\prime} 14.0^{\prime \prime} \mathrm{E}$ \\
Senai & $\mathrm{SS} 18$ & $1^{\circ} 38^{\prime} 20.3^{\prime \prime} \mathrm{N}$ & $103^{\circ} 39^{\prime} 57.0^{\prime \prime} \mathrm{E}$ \\
\hline
\end{tabular}

\section{ARIMA Model}

In time series analysis, the Box-Jenkins method is the commonly used method to model a wind speed time series data. The first step is model identification which include measuring the stability of the mean and the stationarity of the time series. The transformation approach is needed if the data does not satisfy these conditions. This can be done by observing the time series and ACF plots of the collected wind speed data. A hypothesis testing using the 


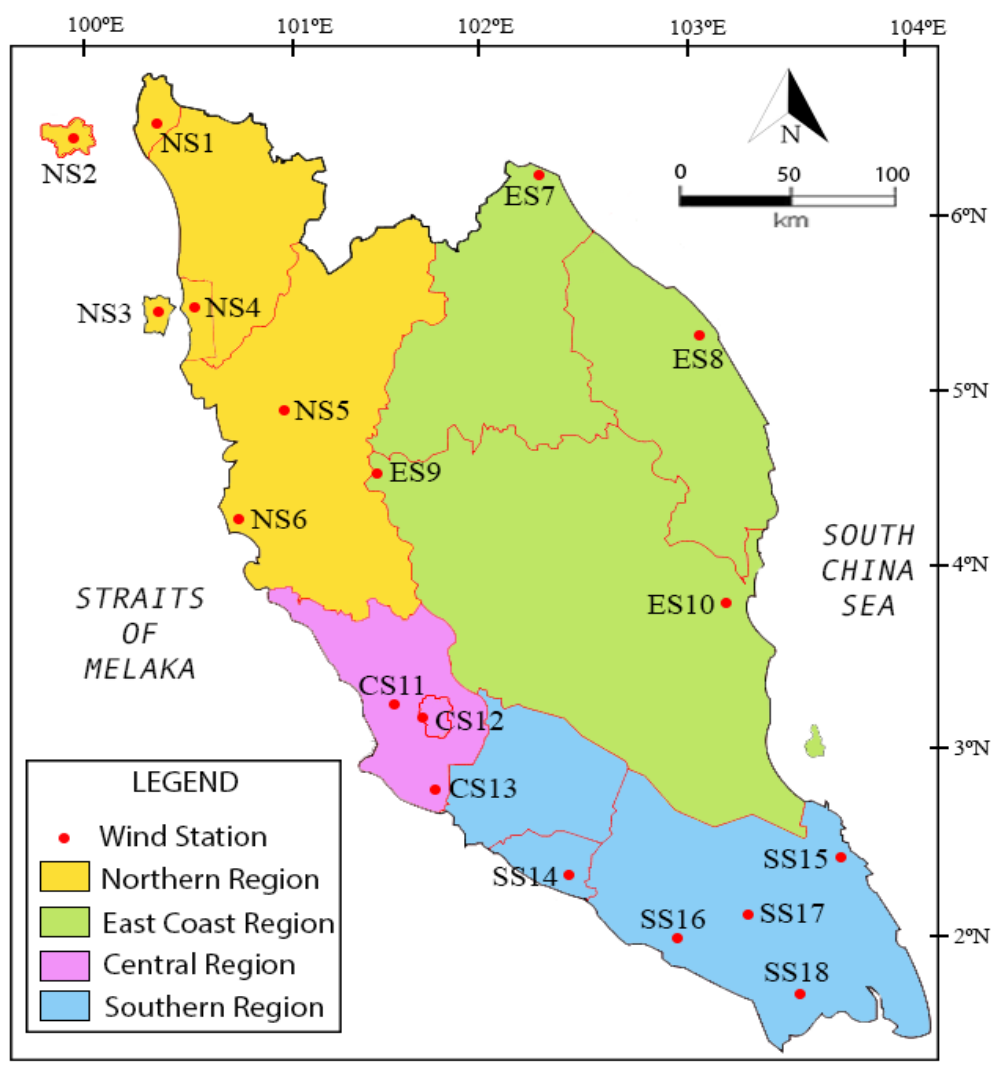

Figure 1. Location of wind stations in Peninsular Malaysia

Kwiatkowski-Phillips-Schmidt-Shin (KPSS) test can be used to determine the stationarity of the wind speed time series data, where the null hypothesis is the data series is stationary (Kwiatkowski et al., 1992). The formulation for the KPSS test is given by Equation 1:

$$
y_{t}=\beta t+r_{t}+\varepsilon_{t}
$$

Note that $r_{-} t=r_{-}(t-1)+u_{-} t$, where $r_{-} t$ represents a random walk while $u_{-} t$ are iid $\left(0, \sigma \_u^{\wedge} 2\right)$. For a p-value that is significantly low than 0.05 , the null hypothesis will be rejected which indicates that the wind speed series in not stationary and requires a differencing approach. For the model selection, autocorrelation function (ACF) and partial autocorrelation function (PACF) plot provides the information on the potential models where it identifies the number of terms for autoregressive order $\mathrm{p}$ and moving average order q (Miswan et al., 2015). 
The general form of autoregressive integrated moving average ARIMA (p, d, q) can be defined as Equation 2:

$$
\varphi(B)(1-B)^{d} y_{t}=\theta(B) \varepsilon_{t}
$$

where $y_{-} \mathrm{t}$ and $\varepsilon_{-} \mathrm{t}$ are the observed values of wind speed series and the random error terms at time period $t$, respectively. $\varphi_{-} 1, \varphi_{-} 2, \varphi_{-} 3, \ldots, \varphi \_p$ are the autoregressive coefficients with order $\mathrm{p} . \mathrm{d}$ is the order of differencing, and $\theta_{-} 1, \theta \_2, \theta \_3, \ldots, \theta_{-} \mathrm{q}$ are the moving average coefficients with order $q$. $B$ is the backward shift operator, while, $\varphi(B)$ and $\theta(B)$ are polynomials of order $\mathrm{p}$ and $\mathrm{q}$ respectively, and defined as follows (Wang et al., 2015):

$$
\begin{aligned}
& \varphi(B)=1-\varphi_{1} B-\varphi_{2} B^{2}-\cdots-\varphi_{p} B^{p} \\
& \theta(B)=1-\theta_{1} B-\theta_{2} B^{2}-\cdots-\theta_{q} B^{q} .
\end{aligned}
$$

\section{Serial Correlation}

A statistical inference of time series analysis will be affected by the presence of serial correlation. A fitted model is appropriate or accurate if the residuals has the conditions of zero mean, homoscedastic, independent, and normally distributed (Jamaludin et al., 2016; Yürekli et al., 2005). One of the very useful diagnostic tools to measure the existence of a serial autocorrelation for residuals in the stationary ARIMA model is using the LjungBox (LB) test (Kim et al., 2004). The null hypothesis was set to the absence of serial autocorrelation in the residuals from the ARIMA model and was performed towards the residuals of a fitted ARIMA model instead of the original time series data. The decision making for the test is based on Equation 3:

$$
Q=T(T+2) \sum_{k=1}^{L} \frac{r_{k}^{2}}{(T-k)} ;
$$

where $\mathrm{T}$ is denoted as the length of the time series, $\mathrm{k}$ represents the number of parameters to be estimated in the model, $\mathrm{r}_{\mathrm{k}} \mathrm{k}^{\wedge} 2$ denotes the sample autocorrelation at lag $\mathrm{k}$, and $\mathrm{L}$ is the number of autocorrelation lag to be tested. The Q-statistics in Equation 3 approximately follows a chi-square distribution with L degree of freedom (Wang et al., 2015).

\section{The Autoregressive Conditional Heteroscedasticity (ARCH) Effect}

Besides checking for the presence of serial correlation, the test to check on the existence of heteroscedasticity in the residual of the model should also be performed. The result can 
also be supported by performing ARCH Lagrange Multiplier (LM) test to determine the existence of heteroscedasticity in the residuals of the model.

\section{Engle's Lagrange Multiplier Test for the ARCH Effect}

Uncorrelated time series models might still have a serial dependence due to the dynamic conditional variance process. The existence of an ARCH effect in the ARIMA model occur if the model exhibits autoregressive conditional heteroscedasticity. If the ARCH effect is neglected, the consequences might result to large arbitrary loses in asymptotic efficiency which will lead to an extreme rejection of the standard test for the mean autocorrelation (Sjölander, 2011). To assess the significance of an ARCH effect, Engle (1982) proposed a methodology using Lagrange Multiplier (LM) test to assess the presence of ARCH effect based on the regression. The decision making of this test is based on Equation 4:

$$
e_{t}^{2}=\hat{a}_{0}+\sum_{s=1}^{q} \hat{a}_{s} e_{t-s}^{2}
$$

where $e_{-} t$ is the residual series and a_s is the estimated coefficients of the fitted model. In this test, the null hypothesis is set to be that there is no existing ARCH component up to order q; i.e. a_s $=0$ for all $\mathrm{s}=1,2, \ldots$, q. The alternative hypothesis is there are presence of ARCH components in at least one of the estimated a_s coefficients (Yusof et al., 2013). The test statistics for this test is given by TR2. It follows a chi-square distribution with $\mathrm{q}$ degree of freedom, where $\mathrm{R}$ denotes the sample multiple correlation coefficient based on the computation from the regression in Equation 4, and $\mathrm{T}$ is the number of observations (Wang et al., 2005).

\section{The GARCH Model}

Generalized Autoregressive Conditional Heteroscedastic (GARCH) model was developed by Bollerslev (1986). It helps the ARIMA (p, d, q) model to capture the heteroscedastic effect in a time series process. In modelling a univariate time series, let $y_{-} t=\mu_{-} t+\varepsilon_{-} t$ denote the mean equation with respect to time $t$, where the conditional mean of $y_{-} t$ is represented by $\mu_{-} t$, while $\varepsilon_{-} t$ is denoted as the shock at time $t$ and the equation is $\varepsilon_{-} t=v_{-} t \sigma_{-} t$ where it follows a distribution of $\varepsilon_{-} t \sim$ iid $N(0,1)$. Then, the conditional variance of y_t denoted by $\sigma_{-} \mathrm{t}^{\wedge} 2$, that follows a GARCH $(\mathrm{p}, \mathrm{q})$ model can be expressed in Equation 5:

$$
\sigma_{t}^{2}=\propto_{0}+\sum_{i=1}^{p} \propto_{i} \varepsilon_{t-i}^{2}+\sum_{i=1}^{q} \beta_{i} \sigma_{t-i}^{2}
$$


where the value of $\propto_{0}$ is always positive, while the sum of $\propto_{1}$ and $\beta 1$ is less than 1 up to order $\mathrm{p}$ and $\mathrm{q}$. The coefficient of parameters that represent $\mathrm{ARCH}$ and GARCH are represented by $\propto_{i}$ and $\beta_{i}$, respectively.

\section{The ARIMA-GARCH Model}

The ARIMA-GARCH model is known to have two procedures where the first part models the linear part of the wind speed series using ARIMA model, while the residual part consists of the nonlinear data (Yaziz et al., 2013). Then, using the GARCH model, the residuals that display only the nonlinear pattern will be modelled and the combination of the ARIMA model and GARCH error component will give a model that can capture the dynamics of the wind speed series which can be used to forecast wind series. The standard GARCH $(1,1)$ model was used to capture the heteroscedastic effect of the time series process in this study.

\section{Forecasting Accuracy Measures}

The final part of this study was to forecast the wind speed data based on the best fitted proposed model as well as examine the adequacy and accuracy of the proposed model. The adequacy and accuracy checking involve the investigation of the error terms in the proposed model. This study would use RMSE and MAPE as forecasting accuracy measures which are given by Equation 6 and 7:

$$
\begin{aligned}
& \text { RMSE }=\sqrt{\left.\frac{1}{n} \sum_{j=1}^{n} \widehat{(y}_{j}-y_{j}\right)^{2}} ; \\
& M A P E=\frac{1}{n} \sum_{j=1}^{n} \frac{\left.\mid \widehat{(y}_{j}-y_{j}\right) \mid}{y_{j}} \times 100 ;
\end{aligned}
$$

where the sample size is denoted by $n$, while $\widehat{y}_{j}$ is the predicted value based on proposed model at time $j$ and $y_{j}$ is the observed value at time $j$. According to a study by Moreno et al. (2013), the MAPE can be considered as one of the commonly used methods to measure forecasting accuracy since it has a feature that is reliable, easy to interpret, clarity of presentation, support of statistical evaluation, and it uses all the information related to the error (Moreno et al., 2013). The interpretation for the typical MAPE value which was explained by Lewis (1982) are presented in Table 2.

Table 2

Interpretation of typical MAPE values

\begin{tabular}{llllll}
\hline MAPE & Interpretation & & MAPE & Interpretation \\
\cline { 1 - 2 } \cline { 5 - 6 } $10-20$ & Highly accurate forecasting & & $20-50$ & & Reasonable forecasting \\
10 & Good forecasting & & $>50$ & Inaccurate forecasting \\
\hline
\end{tabular}




\section{RESULTS AND DISCUSSION}

\section{Descriptive Statistics}

Figure 2 illustrates the central tendency, the dispersion, and the skewness of the wind speed data. The outliers present in the boxplot for each station represent a high wind speed reading in a certain time and location. The presence of these extreme values in wind speed data is very pronounced in data processing. Based on Figure 2, the median of the data for all wind stations were in the range of $6 \mathrm{~m} / \mathrm{s}$ to $9 \mathrm{~m} / \mathrm{s}$. The dispersion of the data that represented by the tail of the boxplot showed a wide dispersion which also indicates volatility. The boxplot also shows that all stations exhibited a positive skewness. It means that the wind speed series for all stations in Peninsular Malaysia were not normally distributed. Therefore, in order to capture the variability and volatility, the Box-Jenkins methodology was applied to model the wind speed data for all wind stations in Peninsular Malaysia.

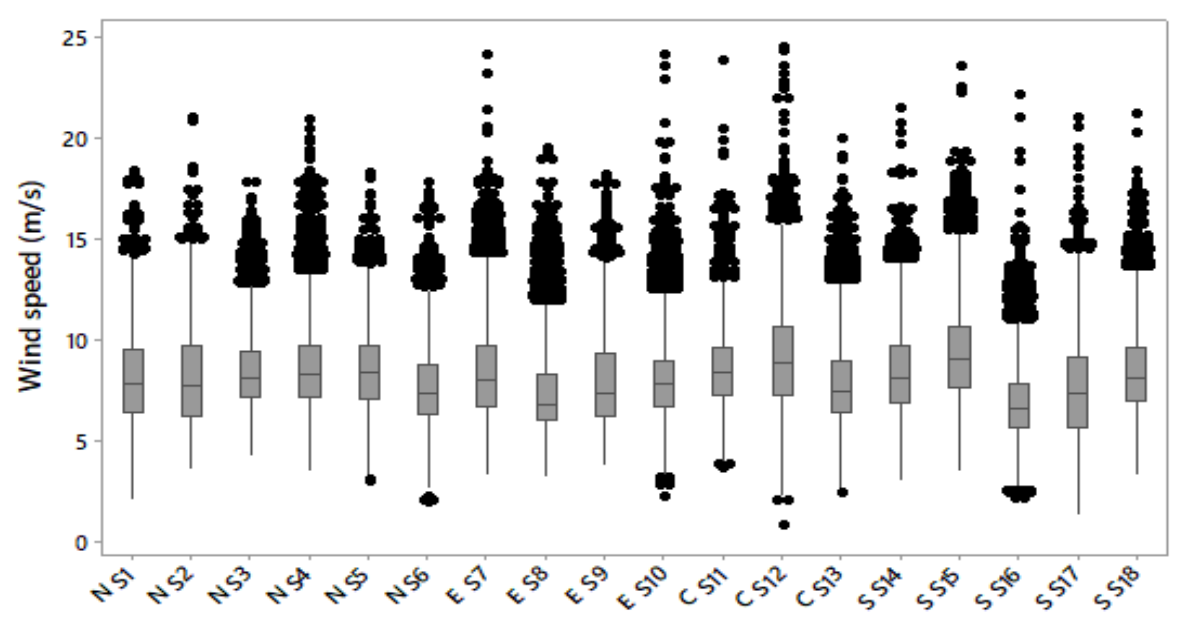

Figure 2. Boxplot of 18 wind stations in Peninsular Malaysia

\section{ARIMA Model}

The first step in building a time series model using the Box-Jenkins methodology is the model identification. This step is intended to determine whether the differencing is required in order to obtain a stationary time series. In practical sense, a stationary time series is known to vary around a constant mean level over time, with a constant variance. This can be determined by observing the time series plot and ACF plot of the wind speed data. It also can be done by performing the Kwiatkowski-Phillips-Schmidt-Shin (KPSS) test, where it tests the presence of a unit root in a time series data. 


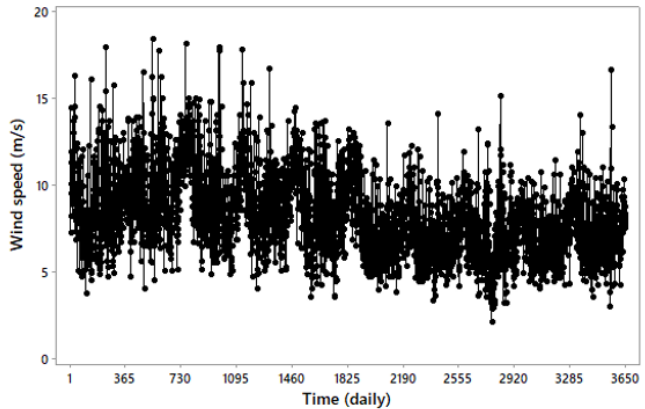

(a)

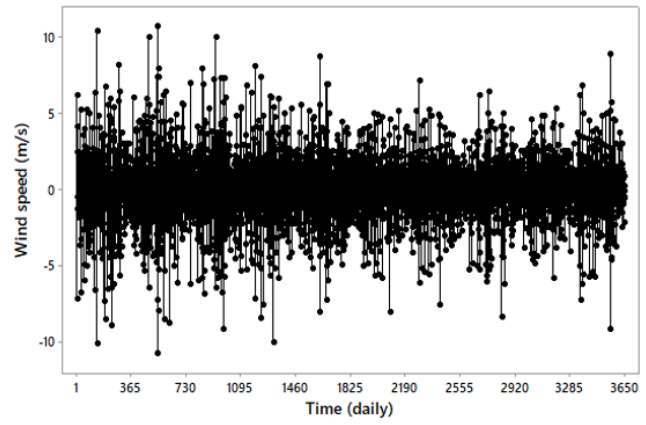

(b)

Figure 3. Time series plot of station NS1; (a) observation data and (b) after first difference.

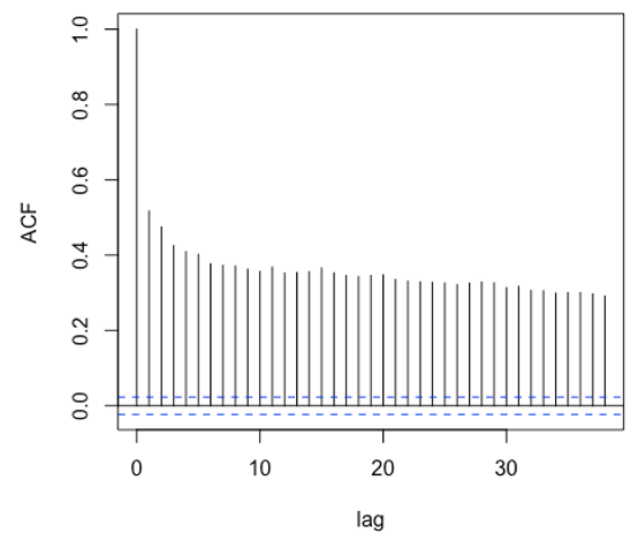

(a)

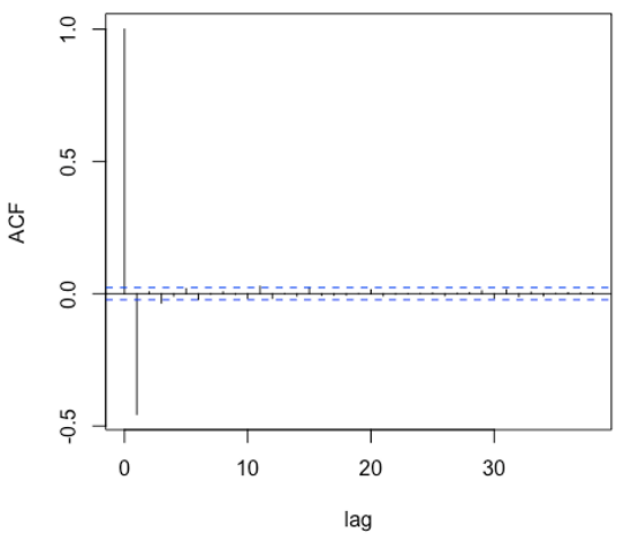

(b)

Figure 4. ACF plot for station NS1; (a) observation data and (b) after first difference.

The time series plot in Figure 3 (a) shows that the mean and variance of wind speed series in station NS1 change over time. This indicates that the time series was not stationary. The plot presented in Figure 4 (a) also proves that station NS1 was not stationary due to the slow decay displayed in the ACF plot. This suggest that the data must undergo differencing. A non-stationary time series can be transformed to stationary if the differences among pairs of observation at lags are calculated. After the first differencing approach was applied, Figure 3 (b) and Figure 4 (b) show that the wind speed data in station NS1 are stationary. To support the findings, the KPSS test was performed to determine the stationarity of the daily wind speed time series data, where the null hypothesis was the data series is stationary. For a p-value that was significantly lower than 0.05 , the null hypothesis would be rejected which indicated that the wind speed series was not stationary and required a differencing 
approach. The results of KPSS test for stationarity are presented in Table 3 where the findings concluded that five stations showed a stationary wind speed series, while 12 other stations satisfied this condition after first differencing $(\mathrm{d}=1)$.

Table 3

The KPSS test for stationarity of the daily wind speed series

\begin{tabular}{lllllll}
\hline \multirow{2}{*}{ Station } & \multicolumn{5}{c}{ Observation Data } & \multicolumn{3}{c}{ First Differencing } \\
\cline { 2 - 7 } & $\begin{array}{l}\text { KPSS } \\
\text { Level }\end{array}$ & p-value & Stationary & $\begin{array}{l}\text { KPSS } \\
\text { Level }\end{array}$ & p-value & Stationary \\
\hline NS1 & 20.699 & $<0.01$ & NO & 0.0012 & $>0.1$ & YES \\
NS2 & 0.0619 & $>0.1$ & YES & - & - & - \\
NS3 & 0.0827 & $>0.1$ & YES & - & - & - \\
NS4 & 3.8562 & $<0.01$ & NO & 0.0028 & $>0.1$ & YES \\
NS5 & 3.1419 & $<0.01$ & NO & 0.0011 & $>0.1$ & YES \\
NS6 & 20.181 & $<0.01$ & NO & 0.0015 & $>0.1$ & YES \\
ES7 & 14.028 & $<0.01$ & NO & 0.0012 & $>0.1$ & YES \\
ES8 & 24.312 & $<0.01$ & NO & 0.0010 & $>0.1$ & YES \\
ES9 & 0.2554 & $>0.1$ & YES & - & - & - \\
ES10 & 25.534 & $<0.01$ & NO & 0.0008 & $>0.1$ & YES \\
CS11 & 0.0848 & $>0.1$ & YES & - & - & - \\
CS12 & 2.000 & $<0.01$ & NO & 0.0015 & $>0.1$ & YES \\
CS13 & 3.0304 & $<0.01$ & NO & 0.0013 & $>0.1$ & YES \\
SS14 & 9.7655 & $<0.01$ & NO & 0.0009 & $>0.1$ & YES \\
SS15 & 5.3813 & $<0.01$ & NO & 0.0011 & $>0.1$ & YES \\
SS16 & 1.9574 & $<0.01$ & NO & 0.0026 & $>0.1$ & YES \\
SS17 & 22.39 & $<0.01$ & NO & 0.0016 & $>0.1$ & YES \\
SS18 & 0.2095 & $>0.1$ & YES & - & - & - \\
\hline & & & & & &
\end{tabular}

After satisfying the stationarity condition, the next step in Box-Jenkins method is the parameter estimation. In this step, the orders of $A R(p)$ and MA(q) for each station were identified using the PACF and ACF plots, respectively. Figure 5 illustrates the ACF plot and PACF plot of station NS1 after first differencing approach is done. 

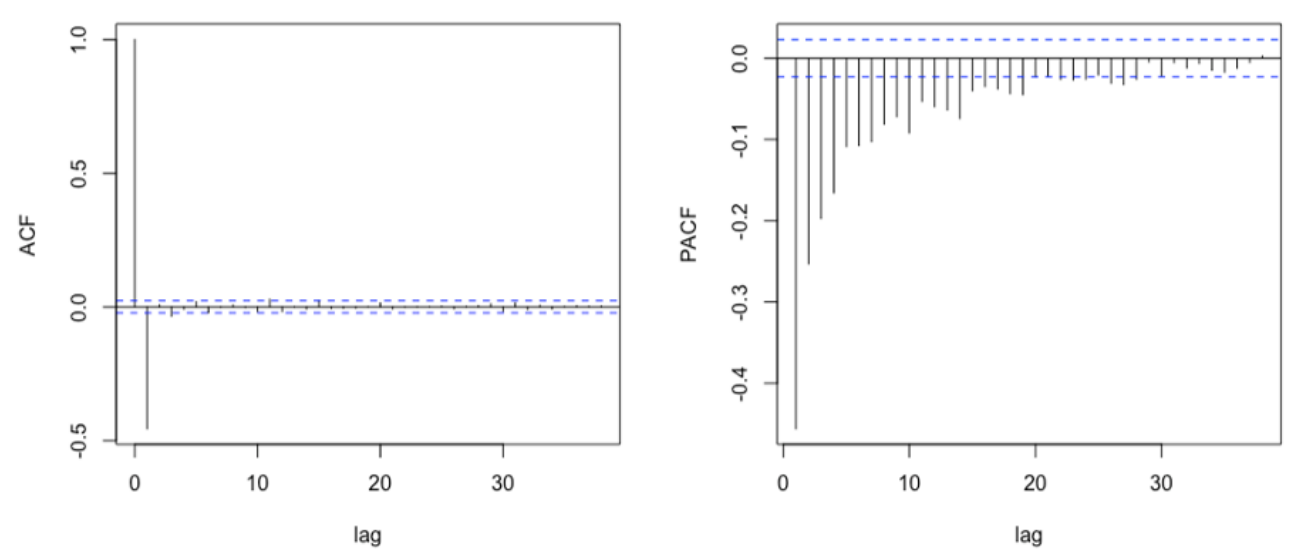

Figure 5. ACF and PACF plot for station NS1 after first difference

Few models were selected for ARIMA (p, d, q) based on these two plots, and the best model was selected based on the Akaike information criterion (AIC) values where the model with the lowest AIC value was selected as the best model for ARIMA model estimation. These steps were repeated on the remaining stations and the results of the best fitted ARIMA model for wind speed series for each station are shown in the Table 4.

Table 4

Model parameter estimates using the ARIMA $(p, d, q)$ model for daily wind speed series

\begin{tabular}{llllll}
\hline Location & Station & Model & Coefficient & Estimates & $\begin{array}{l}\text { Standard } \\
\text { Error }\end{array}$ \\
\hline Chuping & NS1 & ARIMA & AR(1) & 0.1858 & 0.0134 \\
& & $(2,1,1)$ & AR(2) & 0.1031 & 0.0132 \\
Langkawi & \multirow{2}{*}{ NS2 } & ARIMA & AR(1) & -0.9329 & 0.0057 \\
& & $(1,0,1)$ & MA(1) & -0.5106 & 0.0628 \\
Bayan Lepas & \multirow{2}{*}{ NS3 } & ARIMA & AR(1) & 0.8738 & 0.0709 \\
& & $(1,0,1)$ & MA(1) & -0.8338 & 0.0892 \\
Butterworth & \multirow{2}{*}{ NS4 } & ARIMA & AR(1) & 0.4906 & 0.0583 \\
& & $(1,1,2)$ & MA(1) & -1.3395 & 0.0625 \\
& & & MA(2) & 0.3432 & 0.0621 \\
\hline
\end{tabular}


Table 4 (Continued)

\begin{tabular}{|c|c|c|c|c|c|}
\hline Location & Station & Model & Coefficient & Estimates & $\begin{array}{l}\text { Standard } \\
\text { Error }\end{array}$ \\
\hline \multirow[t]{3}{*}{ Lubok Merbau } & \multirow[t]{3}{*}{ NS5 } & \multirow{3}{*}{$\begin{array}{l}\text { ARIMA } \\
(1,1,2)\end{array}$} & $\operatorname{AR}(1)$ & 0.6452 & 0.0863 \\
\hline & & & $\operatorname{MA}(1)$ & -1.5047 & 0.0930 \\
\hline & & & MA(2) & 0.5198 & 0.0883 \\
\hline \multirow[t]{4}{*}{ Sitiawan } & \multirow[t]{4}{*}{ NS6 } & \multirow{4}{*}{$\begin{array}{l}\text { ARIMA } \\
(3,1,1)\end{array}$} & $\mathrm{AR}(1)$ & 0.0910 & 0.0127 \\
\hline & & & $\mathrm{AR}(2)$ & 0.0246 & 0.0126 \\
\hline & & & $\operatorname{AR}(3)$ & -0.0184 & 0.0126 \\
\hline & & & $\mathrm{MA}(1)$ & -0.9557 & 0.0043 \\
\hline \multirow[t]{3}{*}{ Kota Bharu } & \multirow[t]{3}{*}{ ES7 } & \multirow{3}{*}{$\begin{array}{l}\text { ARIMA } \\
(1,1,2)\end{array}$} & $\operatorname{AR}(1)$ & 0.5605 & 0.0322 \\
\hline & & & MA(1) & -1.3219 & 0.0367 \\
\hline & & & $\mathrm{MA}(2)$ & 0.3249 & 0.0365 \\
\hline \multirow{3}{*}{$\begin{array}{l}\text { Kuala } \\
\text { Terengganu }\end{array}$} & \multirow[t]{3}{*}{ ES8 } & \multirow{3}{*}{$\begin{array}{l}\text { ARIMA } \\
(2,1,1)\end{array}$} & $\mathrm{AR}(1)$ & 0.2803 & 0.0125 \\
\hline & & & $\mathrm{AR}(2)$ & 0.0915 & 0.0124 \\
\hline & & & $\operatorname{MA}(1)$ & -0.9849 & 0.0062 \\
\hline \multirow{2}{*}{$\begin{array}{l}\text { Cameron } \\
\text { Highland }\end{array}$} & \multirow[t]{2}{*}{ ES9 } & \multirow{2}{*}{$\begin{array}{l}\text { ARIMA } \\
(2,0,0)\end{array}$} & $\mathrm{AR}(1)$ & 0.4921 & 0.0261 \\
\hline & & & $\mathrm{AR}(2)$ & 0.0305 & 0.0262 \\
\hline \multirow[t]{3}{*}{ Kuantan } & \multirow[t]{3}{*}{ ES10 } & \multirow{3}{*}{$\begin{array}{l}\text { ARIMA } \\
(2,1,1)\end{array}$} & $\operatorname{AR}(1)$ & 0.0919 & 0.0118 \\
\hline & & & $\mathrm{AR}(2)$ & 0.0675 & 0.0117 \\
\hline & & & $\mathrm{MA}(1)$ & -0.9770 & 0.0048 \\
\hline \multirow[t]{2}{*}{ Subang } & \multirow[t]{2}{*}{ CS11 } & \multirow{2}{*}{$\begin{array}{l}\text { ARIMA } \\
(1,0,1)\end{array}$} & $\operatorname{AR}(1)$ & 0.9522 & 0.0291 \\
\hline & & & $\mathrm{MA}(1)$ & -0.9254 & 0.0355 \\
\hline \multirow[t]{3}{*}{ Petaling Jaya } & \multirow[t]{3}{*}{ CS12 } & \multirow{3}{*}{$\begin{array}{l}\text { ARIMA } \\
(2,1,1)\end{array}$} & $\operatorname{AR}(1)$ & 0.0552 & 0.0155 \\
\hline & & & $\mathrm{AR}(2)$ & 0.0343 & 0.0154 \\
\hline & & & $\mathrm{MA}(1)$ & -0.9513 & 0.0062 \\
\hline \multirow[t]{2}{*}{ Sepang } & \multirow[t]{2}{*}{ CS13 } & \multirow{2}{*}{$\begin{array}{l}\text { ARIMA } \\
(1,1,1)\end{array}$} & $\mathrm{AR}(1)$ & 0.1224 & 0.0137 \\
\hline & & & $\mathrm{MA}(1)$ & -0.9888 & 0.0033 \\
\hline \multirow[t]{3}{*}{ Melaka } & \multirow[t]{3}{*}{ SS14 } & \multirow{3}{*}{$\begin{array}{l}\text { ARIMA } \\
(1,1,2)\end{array}$} & $\operatorname{AR}(1)$ & 0.7459 & 0.0377 \\
\hline & & & MA(1) & -1.5496 & 0.0429 \\
\hline & & & $\operatorname{MA}(2)$ & 0.5629 & 0.0401 \\
\hline Mersing & $\mathrm{SS} 15$ & ARIMA & $\mathrm{AR}(1)$ & 0.6731 & 0.0362 \\
\hline & & $(1,1,2)$ & $\operatorname{MA}(1)$ & -1.4005 & 0.0408 \\
\hline & & & $\operatorname{MA}(2)$ & 0.4196 & 0.0370 \\
\hline
\end{tabular}


Table 4 (Continued)

\begin{tabular}{llllll}
\hline Location & Station & Model & Coefficient & Estimates & $\begin{array}{l}\text { Standard } \\
\text { Error }\end{array}$ \\
\hline Batu Pahat & SS16 & ARIMA & AR(1) & 0.8653 & 0.0469 \\
& & $(1,1,2)$ & MA(1) & -1.7653 & 0.0529 \\
\multirow{2}{*}{ Kluang } & & MA(2) & 0.7686 & 0.0517 \\
& \multirow{2}{*}{ SS17 } & ARIMA & AR(1) & 0.7066 & 0.0524 \\
& & $(1,1,2)$ & MA(1) & -1.5504 & 0.0580 \\
\multirow{2}{*}{ Senai } & & MA(2) & 0.5648 & 0.0549 \\
& \multirow{2}{*}{ SS18 } & ARIMA & AR(1) & 0.9352 & 0.0214 \\
& & $(1,0,1)$ & MA(1) & -0.8738 & 0.0301 \\
\hline
\end{tabular}

After parameter estimation, the next step of the Box-Jenkins methodology is model diagnostic checking. In this step, the residual of a fitted ARIMA model was tested for the presence of serial autocorrelation and heteroscedasticity.

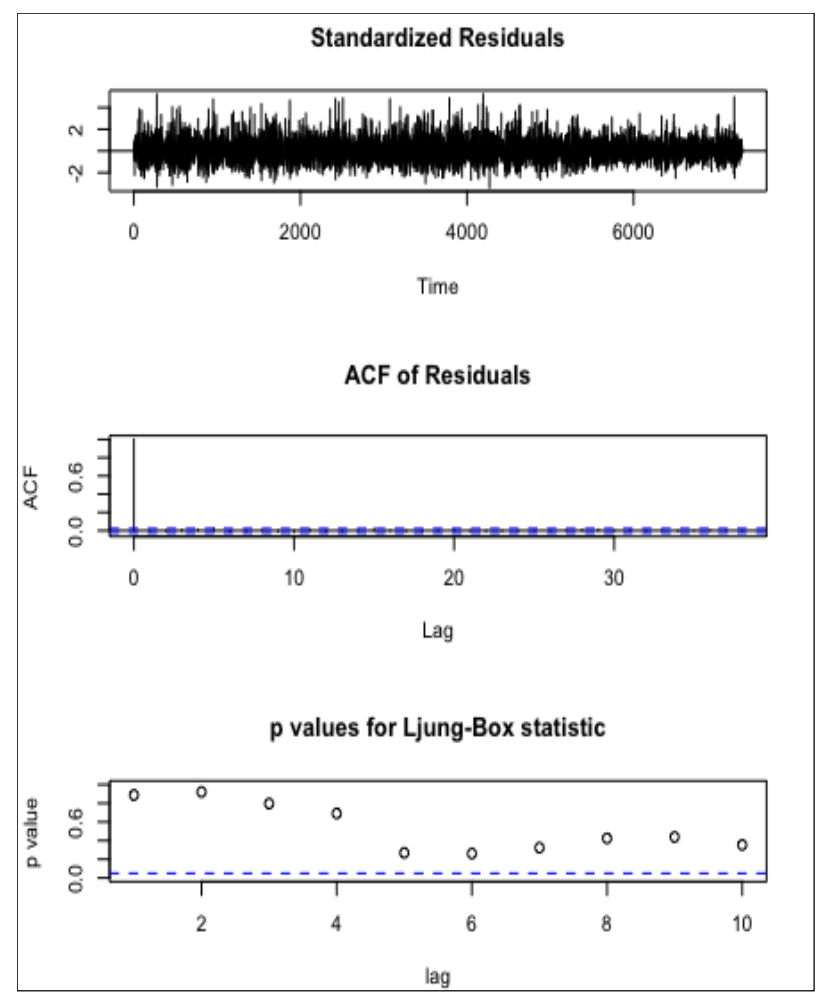

Figure 6. Diagnostic checking results for station NS1 
Figure 6 shows the results of diagnostic checking using the Ljung-Box test for station NS1. The null hypothesis for the Ljung-Box test was set to be no serial autocorrelation in the residual of the fitted ARIMA (p, d, q) model. Based on the plot, the residuals of the wind speed series in station NS1 has a zero mean and constant variance. The ACF plot exhibits no correlation in the residuals of the series. The p-value for Ljung-Box test also confirmed that the residuals of the series were uncorrelated. This step was performed towards the remaining stations and the results are simplified in Table 5. The results of Ljung-Box test for the residuals in Table 5 are given into two parts; the figures represent the p-values for residuals up to lag 10 followed by the p-value for residuals up to lag 20 . In addition, to prove that the square residuals are not a sequence of white noise, the Ljung-Box test was also performed on the squared residual of the wind speed series.

Table 5

The Ljung-Box test for the residuals and squared residuals of the fitted ARIMA $(p, d, q)$ model of daily wind speed series

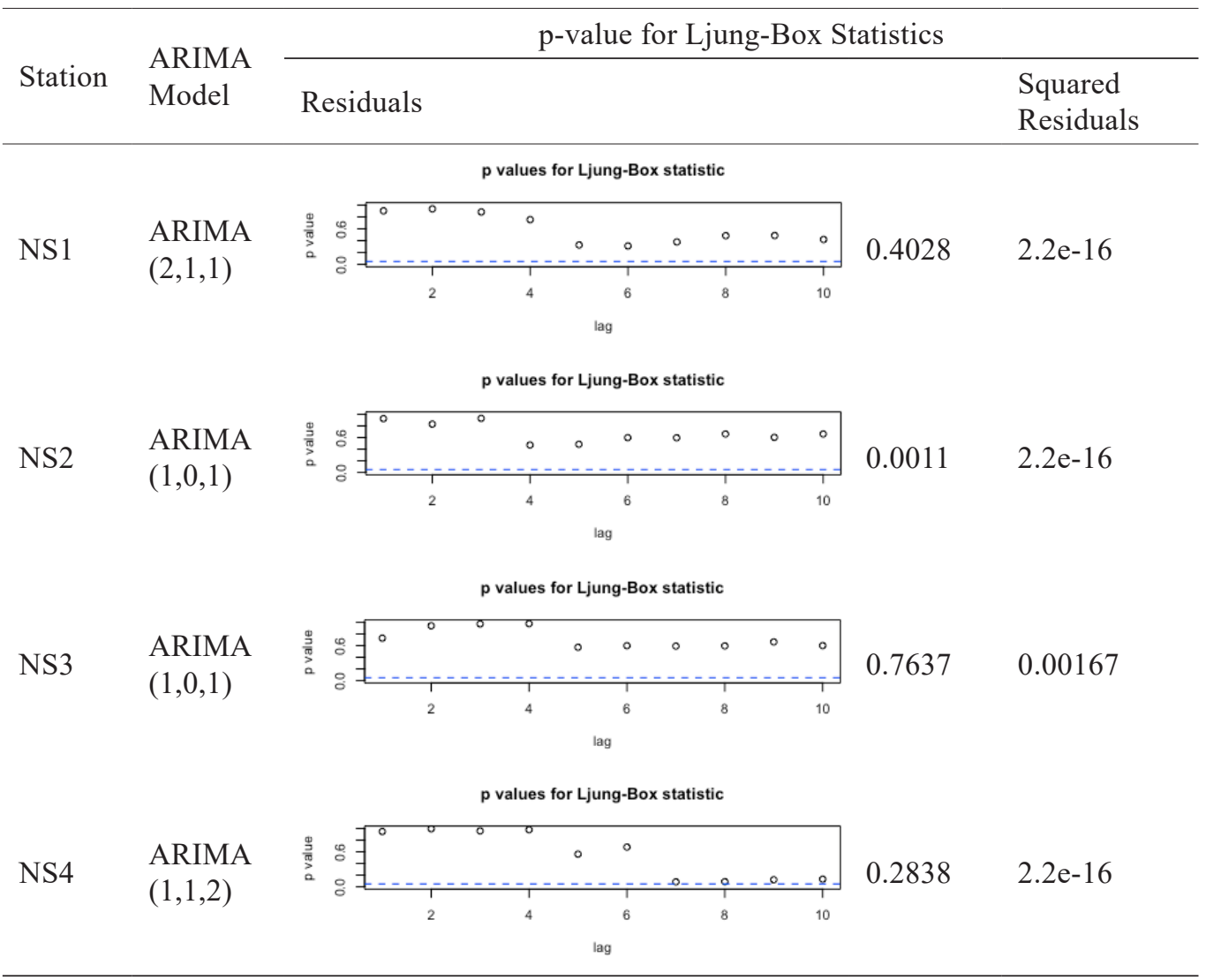


Table 5 (Continued)

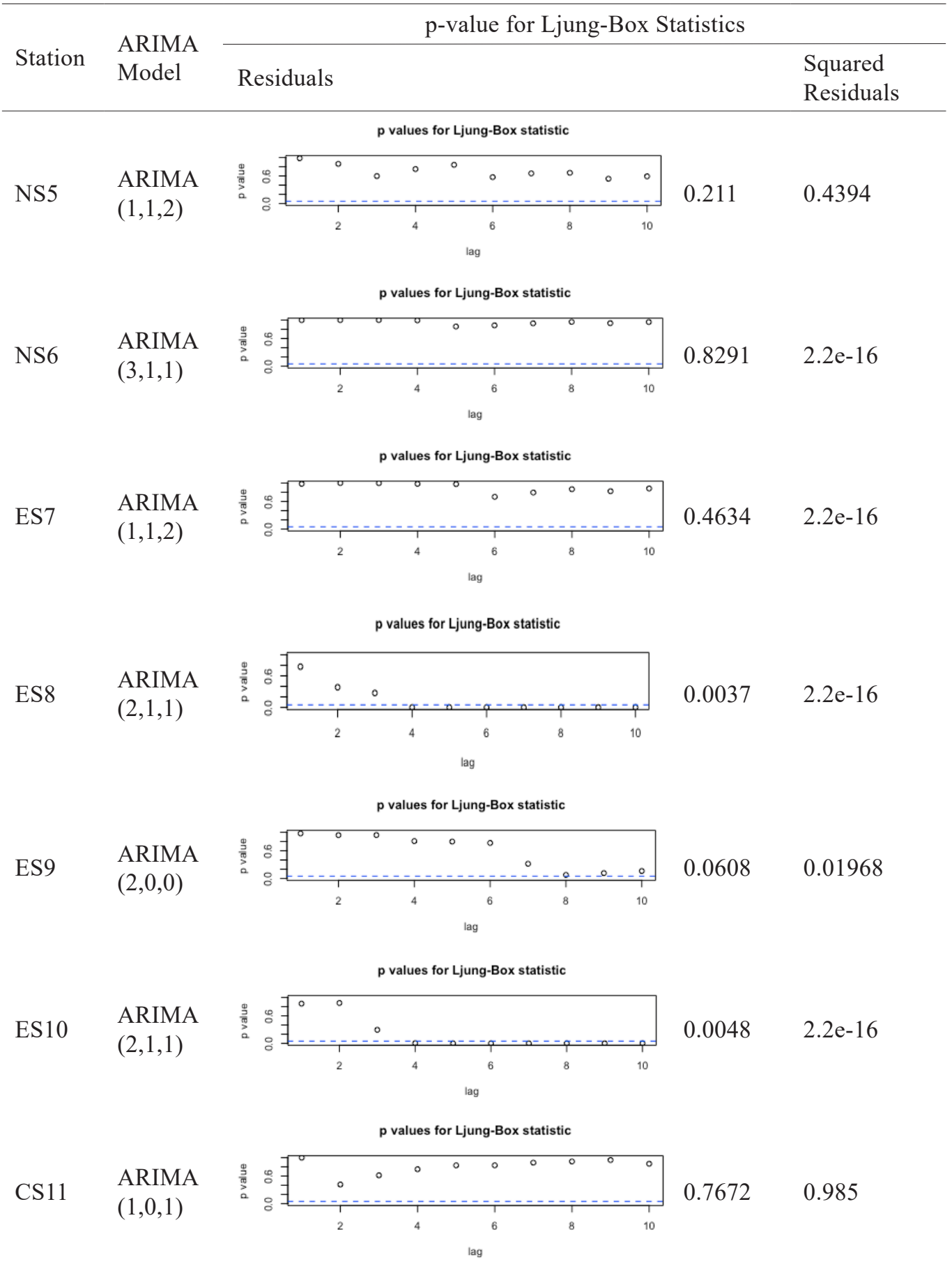


Table 5 (Continued)

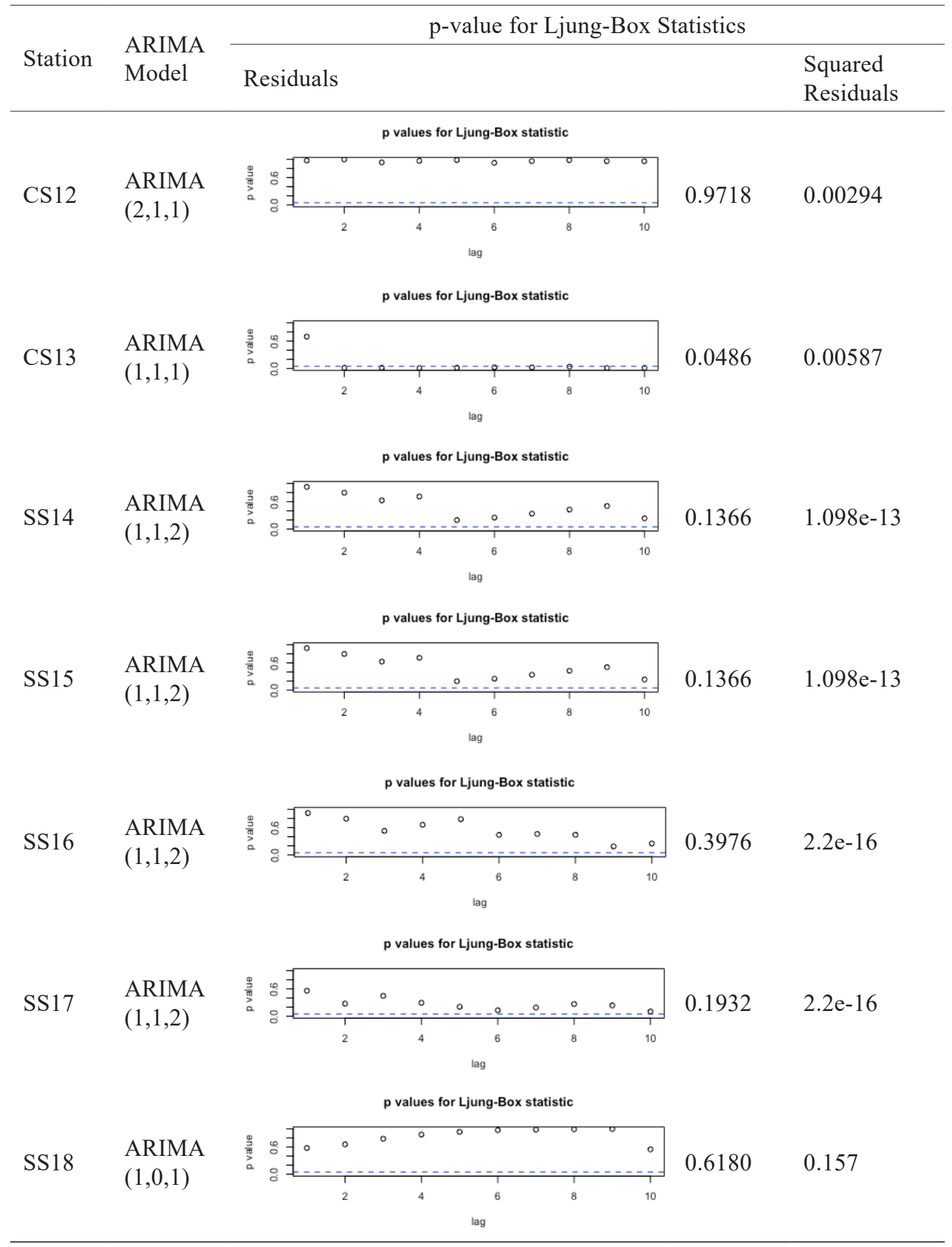


Table 5 shows that the p-values of the Ljung-Box test for stations NS2, ES8, ES10, and CS13 show a clear evidence to reject the null hypothesis of no serial autocorrelation. It means that the wind speed daily series in these stations shows the presence of autocorrelation in the residual of the series. Other stations did not show the presence of serial autocorrelation in the residual of the daily wind speed series. On the other hand, the Ljung-Box test for the squared residuals with a p-value less than 0.05 indicates the presence of ARCH effect in the residuals of the series. Based on the results presented in Table 5, three stations were found to be not affected by ARCH effect, which was station NS5, CS11, and SS18. The remaining 15 stations showed that the residuals were a sequence of white noise which also indicated the presence of ARCH effect in the daily wind speed series. Therefore, to conclude on the presence of heteroscedasticity in the series, the LM test was applied towards the residuals of the fitted ARIMA models and the result are presented in Table 6. The null hypothesis for this test is there is no ARCH effect presence in the residual of the models. For a p-value that is lower than 0.05 , the null hypothesis is rejected which indicates that the model residuals significantly exhibit an ARCH effect.

Table 6

The LM test for the residuals of the fitted ARIMA $(p, d, q)$ model of daily wind speed series

\begin{tabular}{llll}
\hline Station & ARIMA Model & Residuals & Squared Residuals \\
\cline { 3 - 4 } & & p-value & p-value \\
\hline NS1 & ARIMA $(2,1,1)$ & $2.2 \mathrm{e}-16$ & $1.928 \mathrm{e}-05$ \\
NS2 & ARIMA $(1,0,1)$ & $1.029 \mathrm{e}-08$ & 0.9162 \\
NS3 & ARIMA $(1,0,1)$ & 0.0449 & 0.0471 \\
NS4 & ARIMA $(1,1,2)$ & $2.2 \mathrm{e}-16$ & 0.0110 \\
NS5 & ARIMA $(1,1,2)$ & 0.4922 & 1 \\
NS6 & ARIMA $(3,1,1)$ & $2.2 \mathrm{e}-16$ & $2.2 \mathrm{e}-16$ \\
ES7 & ARIMA $(1,1,2)$ & $2.2 \mathrm{e}-16$ & 0.9999 \\
ES8 & ARIMA $(2,1,1)$ & $2.2 \mathrm{e}-16$ & 0.2241 \\
ES9 & ARIMA $(2,0,0)$ & 0.0414 & 0.9448 \\
ES10 & ARIMA $(2,1,1)$ & $2.2 \mathrm{e}-16$ & 0.9847 \\
CS11 & ARIMA $(1,0,1)$ & 0.9865 & 1 \\
CS12 & ARIMA $(2,1,1)$ & 0.0056 & 0.9338 \\
CS13 & ARIMA $(1,1,1)$ & 0.0175 & 0.9995 \\
SS14 & ARIMA $(1,1,2)$ & $3.228 \mathrm{e}-06$ & 0.5071 \\
SS15 & ARIMA $(1,1,2)$ & $2.997 \mathrm{e}-11$ & 1 \\
SS16 & ARIMA $(1,1,2)$ & $2.834 \mathrm{e}-16$ & 0.3848 \\
\hline
\end{tabular}


Table 6 (Continued)

\begin{tabular}{llll}
\hline Station & ARIMA Model & Residuals & Squared Residuals \\
\cline { 3 - 4 } & & p-value & p-value \\
\hline SS17 & ARIMA $(1,1,2)$ & $2.2 \mathrm{e}-16$ & 0.0007 \\
SS18 & ARIMA $(1,0,1)$ & 0.1865 & 1 \\
\hline
\end{tabular}

The results in Table 6 show that the 3 stations; NS5, CS11, and SS18 were not affected by the heteroscedasticity effect based on the p-values of the residuals of the LM test. This was also supported by the Ljung-Box test in Table 5 for squared residuals. Hence, it can be concluded that the proposed ARIMA model for these 3 stations are suitable for forecasting the daily wind speed series in the respective location. On the other hand, the remaining 15 stations verify that the ARCH effect was established in the wind speed daily series for these stations. Therefore, to cater the issue of the presence of serial autocorrelation and ARCH effect in the residual of fitted ARIMA ( $\mathrm{p}, \mathrm{d}, \mathrm{q}$ ) model, GARCH modelling is necessary to model the nonlinear part of the daily wind speed series.

\section{ARIMA-GARCH Modelling}

The ARIMA model explains the linear part of the data, while the nonlinear characteristics is explained using the GARCH model which is derived based on the residual series of an ARIMA model. In this study, the method used to model the variance behavior was using the standard GARCH $(1,1)$ model.

Table 7

The result for the estimated ARIMA-GARCH model for wind speed data in Malaysia

\begin{tabular}{|c|c|c|c|c|c|c|c|}
\hline \multirow{2}{*}{ Station } & \multirow{2}{*}{ Model } & \multicolumn{4}{|c|}{ Parameter Estimates } & \multirow{2}{*}{$\begin{array}{l}\text { Ljung-Box } \\
\text { Test } \\
\text { p-value }\end{array}$} & \multirow{2}{*}{$\begin{array}{c}\text { LM Test } \\
\text { p-value }\end{array}$} \\
\hline & & $\mu$ & $\omega$ & $\alpha$ & $\beta$ & & \\
\hline NS1 & $\begin{array}{l}\text { ARIMA } \\
(2,1,1)- \\
\text { GARCH } \\
(1,1)\end{array}$ & 0.0053 & 0.3363 & 0.0975 & 0.8176 & 0.0521 & 0.0131 \\
\hline NS2 & $\begin{array}{l}\text { ARIMA } \\
(1,0,1)- \\
\text { GARCH } \\
(1,1)\end{array}$ & 8.1178 & 1.0888 & 0.1384 & 0.6731 & 0.9053 & 0.9722 \\
\hline
\end{tabular}


Table 7 (Continued)

\begin{tabular}{|c|c|c|c|c|c|c|c|}
\hline \multirow{2}{*}{ Station } & \multirow{2}{*}{ Model } & \multicolumn{4}{|c|}{ Parameter Estimates } & \multirow{2}{*}{$\begin{array}{l}\text { Ljung-Box } \\
\text { Test } \\
\text { p-value }\end{array}$} & \multirow{2}{*}{$\begin{array}{l}\text { LM Tes } \\
p \text {-value }\end{array}$} \\
\hline & & $\mu$ & $\omega$ & $\alpha$ & $\beta$ & & \\
\hline NS3 & $\begin{array}{l}\text { ARIMA } \\
(1,0,1)- \\
\text { GARCH } \\
(1,1)\end{array}$ & 8.4873 & 0.3458 & 0.0638 & 0.8489 & 0.9762 & 0.9510 \\
\hline NS4 & $\begin{array}{l}\text { ARIMA } \\
(1,1,2)- \\
\text { GARCH } \\
(1,1)\end{array}$ & 0.0003 & 0.0645 & 0.0258 & 0.9615 & 0.0000 & 0.1256 \\
\hline NS6 & $\begin{array}{l}\text { ARIMA } \\
(3,1,1)- \\
\text { GARCH } \\
(1,1)\end{array}$ & 0.0018 & 0.0936 & 0.0362 & 0.9376 & 0.2195 & 0.0812 \\
\hline ES7 & $\begin{array}{l}\text { ARIMA } \\
(1,1,2)- \\
\text { GARCH } \\
(1,1)\end{array}$ & -0.0010 & 0.2578 & 0.1092 & 0.8551 & 0.0077 & 0.0902 \\
\hline ES8 & $\begin{array}{l}\text { ARIMA } \\
(2,1,1)- \\
\text { GARCH } \\
(1,1)\end{array}$ & -0.0020 & 0.1026 & 0.1191 & 0.8763 & 0.0000 & 0.0007 \\
\hline ES9 & $\begin{array}{l}\text { ARIMA } \\
(2,0,0)- \\
\text { GARCH } \\
(1,1)\end{array}$ & 7.7551 & 1.7030 & 0.1552 & 0.4489 & 0.6530 & 0.3274 \\
\hline ES10 & $\begin{array}{l}\text { ARIMA } \\
(2,1,1)- \\
\text { GARCH } \\
(1,1)\end{array}$ & 0.0017 & 0.0707 & 0.0543 & 0.9390 & 0.7439 & 0.5164 \\
\hline $\mathrm{CS} 12$ & $\begin{array}{l}\text { ARIMA } \\
(2,1,1)- \\
\text { GARCH } \\
(1,1)\end{array}$ & 0.0005 & 1.6691 & 0.0647 & 0.6595 & 0.4033 & 0.4569 \\
\hline CS13 & $\begin{array}{l}\text { ARIMA } \\
(1,1,1)- \\
\text { GARCH } \\
(1,1)\end{array}$ & 0.0002 & 0.0795 & 0.0169 & 0.9655 & 0.6070 & 0.7862 \\
\hline
\end{tabular}


Table 7 (Continued)

\begin{tabular}{|c|c|c|c|c|c|c|c|}
\hline \multirow{2}{*}{ Station } & \multirow{2}{*}{ Model } & \multicolumn{4}{|c|}{ Parameter Estimates } & \multirow{2}{*}{$\begin{array}{l}\begin{array}{l}\text { Ljung-Box } \\
\text { Test }\end{array} \\
\text { p-value }\end{array}$} & \multirow{2}{*}{$\begin{array}{l}\text { LM Test } \\
\text { p-value }\end{array}$} \\
\hline & & $\mu$ & $\omega$ & $\alpha$ & $\beta$ & & \\
\hline SS14 & $\begin{array}{l}\text { ARIMA } \\
(1,1,2)- \\
\text { GARCH } \\
(1,1)\end{array}$ & 0.0004 & 0.0115 & 0.0124 & 0.9853 & 0.0119 & 0.3177 \\
\hline S S15 & $\begin{array}{l}\text { ARIMA } \\
(1,1,2)- \\
\text { GARCH } \\
(1,1)\end{array}$ & -0.0011 & 1.5383 & 0.1468 & 0.6303 & 0.13388 & 0.22325 \\
\hline S S16 & $\begin{array}{l}\text { ARIMA } \\
(1,1,2)- \\
\text { GARCH } \\
(1,1)\end{array}$ & 0.0000 & 0.2179 & 0.0679 & 0.8831 & 0.7664 & 0.4526 \\
\hline S S17 & $\begin{array}{l}\text { A R I M A } \\
(1,1,2)- \\
\text { G A R C H } \\
(1,1)\end{array}$ & 0.0001 & 0.0103 & 0.0294 & 0.9691 & 0.14448 & 0.7983 \\
\hline
\end{tabular}

Table 7 gives the result of the ARIMA-GARCH model. The mean behaviour of the daily wind speed series was modelled using ARIMA model, while the standard GARCH $(1,1)$ model captured the conditional variance in the residuals of the series. In this case, the GARCH model was used to cater the existence of the ARCH effect in the residual of daily wind speed series. The diagnostic checking was conducted once again on the ARIMA-GARCH model. The Ljung-Box test was used to check the presence of serial autocorrelation in the standardized squared residuals from the GARCH model. Based on the p-values in Table 7, it can be concluded that the serial autocorrelation no longer existed in the model except for 4 stations which were NS4, ES7, ES8, and SS14. The test was performed on the residuals of the hybrid model using the LM test to investigate the existence of remaining ARCH effect in the residuals of the model. The results in Table 7 prove that there was still ARCH effect in stations NS1 and ES8. For the stations NS2, NS3, NS6, ES9, ES10, CS12, CS13, SS15, SS16, and SS17, there was enough evidence to conclude that the daily wind speed series were free from the conditional heteroscedasticity. This shows that the ARIMA-GARCH model has precisely captured the dynamics in the wind speed daily series. However, further investigation should be done to treat the presence of serial autocorrelation in time series data collected from the stations NS4, ES7, ES8, and SS14, and the presence of $\mathrm{ARCH}$ effect in time series data collected from the stations NS1 and 
ES8 using other type of GARCH family models since it has proven to be very successful in describing the volatility dynamics in a short period of time (Jamaludin et al., 2016).

\section{Forecasting Capabilities using ARIMA Model and ARIMA-GARCH Model}

The performance of the proposed model was tested based on the capability of forecasting future daily wind speed series. The model was built using the in-sample data and then was projected for 365 days ahead. This forecasted series that is estimated based on the best fitted model was compared with the last 365 of out-sample data and the accuracy of the forecasting model was evaluated from the RMSE and MAPE values where the lowest value indicates a better performance. The results of RMSE and MAPE between the in-sample and out-sample data are given in Table 8. Forecasting interpretation based on Table 1 is also included in the Table 8 .

Table 8

The result of forecast accuracy using RMSE and MAPE and forecasting interpretation

\begin{tabular}{|c|c|c|c|c|c|c|}
\hline \multirow[t]{2}{*}{ Station } & \multirow[t]{2}{*}{ Model } & \multicolumn{2}{|c|}{ In-Sample } & \multicolumn{2}{|c|}{ Out-Sample } & \multirow{2}{*}{$\begin{array}{l}\text { Forecasting } \\
\text { Interpretation }\end{array}$} \\
\hline & & RMSE & MAPE & RMSE & MAPE & \\
\hline NS2 & $\begin{array}{l}\text { ARIMA } \\
(1,0,1)- \\
\text { GARCH } \\
(1,1)\end{array}$ & 2.4554 & 23.7161 & 2.3163 & 23.7408 & Reasonable \\
\hline NS3 & $\begin{array}{l}\text { ARIMA } \\
(1,0,1)- \\
\text { GARCH } \\
(1,1)\end{array}$ & 1.9921 & 16.907 & 2.1799 & 16.3708 & Good \\
\hline NS5 & $\begin{array}{l}\text { ARIMA } \\
(1,1,2)\end{array}$ & 1.4156 & 13.7443 & 1.4401 & 15.4814 & Good \\
\hline NS6 & $\begin{array}{l}\text { ARIMA } \\
(3,1,1)- \\
\text { GARCH } \\
(1,1)\end{array}$ & 1.4584 & 13.7489 & 1.3166 & 15.2564 & Good \\
\hline ES9 & $\begin{array}{l}\text { ARIMA } \\
(2,0,0)- \\
\text { GARCH } \\
(1,1)\end{array}$ & 2.1346 & 19.8658 & 2.3821 & 20.3147 & Reasonable \\
\hline ES10 & $\begin{array}{l}\text { ARIMA } \\
(2,1,1)- \\
\text { GARCH } \\
(1,1)\end{array}$ & 1.8198 & 14.9371 & 1.6481 & 14.0077 & Good \\
\hline
\end{tabular}


Table 8 (Continued)

\begin{tabular}{|c|c|c|c|c|c|c|}
\hline \multirow[t]{2}{*}{ Station } & \multirow[t]{2}{*}{ Model } & \multicolumn{2}{|c|}{ In-Sample } & \multicolumn{2}{|c|}{ Out-Sample } & \multirow{2}{*}{$\begin{array}{l}\text { Forecasting } \\
\text { Interpretation }\end{array}$} \\
\hline & & RMSE & MAPE & RMSE & MAPE & \\
\hline CS11 & $\begin{array}{l}\text { ARIMA } \\
(1,0,1)\end{array}$ & 2.1572 & 18.8206 & 1.7758 & 17.3518 & Good \\
\hline CS12 & $\begin{array}{l}\text { ARIMA } \\
(2,1,1)- \\
\text { GARCH } \\
(1,1)\end{array}$ & 1.9336 & 17.2430 & 1.8117 & 15.9246 & Good \\
\hline CS13 & $\begin{array}{l}\text { ARIMA } \\
(1,1,1)- \\
\text { GARCH } \\
(1,1)\end{array}$ & 1.5761 & 14.8005 & 1.8743 & 14.3288 & Good \\
\hline SS15 & $\begin{array}{l}\text { ARIMA } \\
(1,1,2)- \\
\text { GARCH } \\
(1,1)\end{array}$ & 1.9593 & 15.0709 & 1.7438 & 13.7584 & Good \\
\hline SS16 & $\begin{array}{l}\text { ARIMA } \\
(1,1,2)- \\
\text { GARCH } \\
(1,1)\end{array}$ & 1.5367 & 14.8042 & 1.3239 & 13.3581 & Good \\
\hline SS17 & $\begin{array}{l}\text { ARIMA } \\
(1,1,2)- \\
\text { GARCH } \\
(1,1)\end{array}$ & 1.6702 & 16.0472 & 1.2368 & 13.4531 & Good \\
\hline SS18 & $\begin{array}{l}\text { ARIMA } \\
(1,0,1)\end{array}$ & 2.0314 & 19.685 & 1.9686 & 17.7601 & Good \\
\hline
\end{tabular}

Table 8 shows that the proposed model could forecast the daily wind speed series where the values of RMSE and MAPE of the out-sample data followed closely the in-sample data for ARIMA model and ARIMA-GARCH model. The values of MAPE for the proposed model shows that 11 out of 13 station (85\%) gave good forecasts while the other 2 stations (15\%) forecasted reasonably well as mentioned in Lewis (1982). Figure 7 shows the distribution of the best fitted model for 13 locations of wind stations in Peninsular Malaysia.

Table 9 shows that the ARIMA and ARIMA-GARCH model could modelled most of the stations in the northern, east coast, central and southern regions. There were 3 stations $(16.68 \%)$ in the northern, central, and southern regions that could be modelled using ARIMA modelling. For ARIMA-GARCH modelling, 10 stations (55.56\%) out of 18 were able to be modelled using the hybrid model. This shows that 13 stations $(72.24 \%)$ out of 18 wind stations in Peninsular Malaysia were successfully modelled using a time 
series modelling. These results have proven the ability of the proposed models for wind speed forecasting and may be used to predict the future pattern of daily wind speed series in Peninsular Malaysia. The results of wind speed prediction can be used to provide a quantitative measure of wind energy available in the potential location for renewable energy conversion (Barbosa de Alencar et al., 2017). Further studies are required for the remaining 5 stations $(27.78 \%$ ) that give a non-conclusive result due to failure in modelling the volatility of the daily wind speed using both ARIMA and ARIMA-GARCH.

To check the forecasting performance of ARIMA-GARCH modelling, the 3 stations that had an adequate model of ARIMA was tested once again using ARIMA-GARCH. The forecasting accuracy measure as mentioned in Lewis (1982) for the out-sample for each station are illustrated in Table 10.

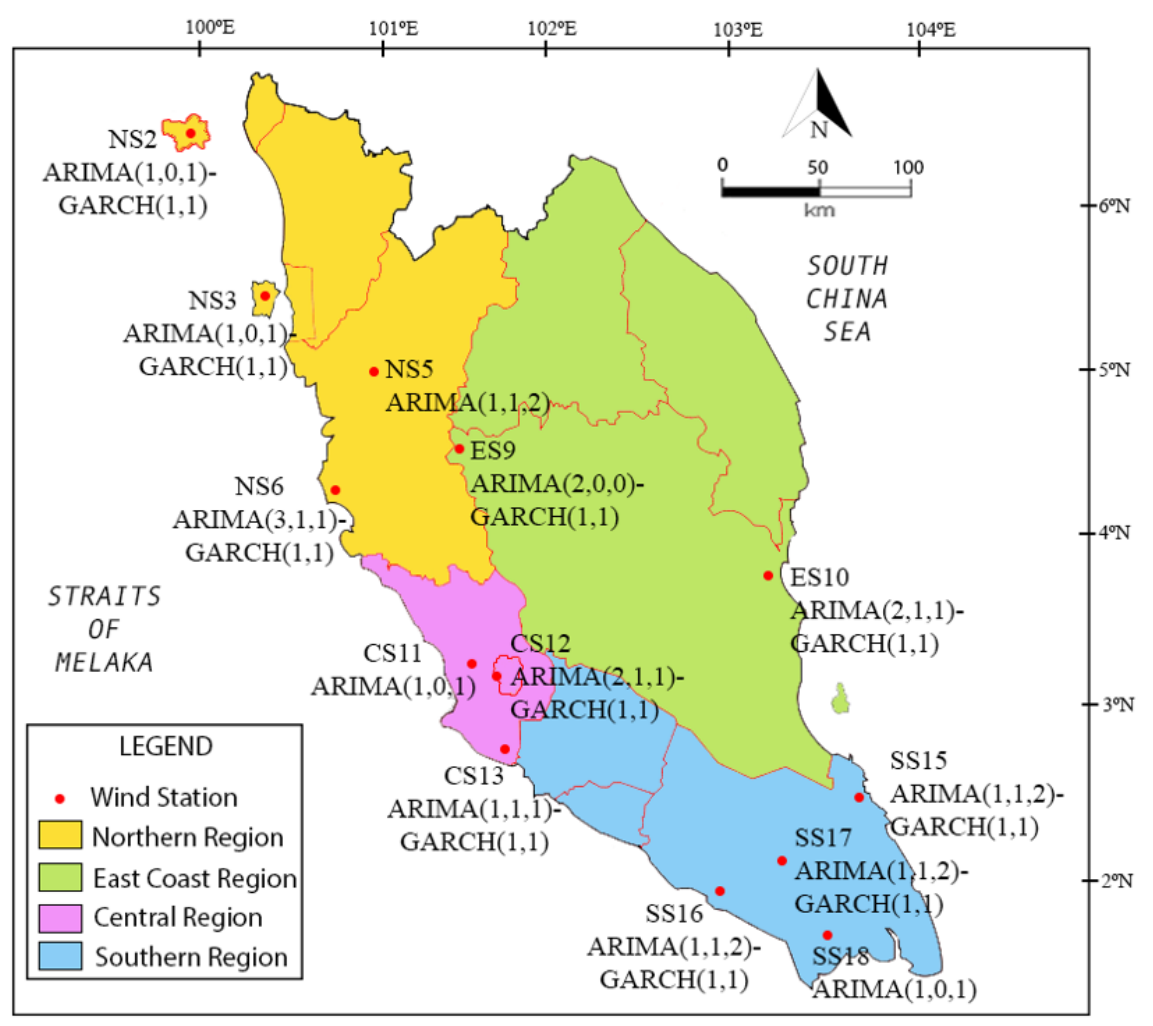

Figure 7. Results of ARIMA and ARIMA-GARCH models 
Table 9

Percentage of proposed model based on region of wind stations

\begin{tabular}{llllllll}
\hline \multirow{2}{*}{ Region } & \multirow{2}{*}{$\begin{array}{l}\text { Total } \\
\text { Station }\end{array}$} & \multicolumn{2}{c}{ ARIMA } & \multicolumn{2}{c}{ ARIMA-GARCH } & \multicolumn{2}{c}{ Non- Conclusive } \\
\cline { 3 - 7 } & & Station & Percent & Station & Percent & Station & Percent \\
\hline North & 6 & 1 & $5.56 \%$ & 3 & $16.67 \%$ & 2 & $11.11 \%$ \\
$\begin{array}{l}\text { East } \\
\text { Coast }\end{array}$ & 4 & 0 & $0 \%$ & 2 & $11.11 \%$ & 2 & $11.11 \%$ \\
Central & 3 & 1 & $5.56 \%$ & 2 & $11.11 \%$ & 0 & $0 \%$ \\
South & 5 & 1 & $5.56 \%$ & 3 & $16.67 \%$ & 1 & $5.56 \%$ \\
Total & 18 & 3 & $16.68 \%$ & 10 & $55.56 \%$ & 5 & $27.78 \%$ \\
\hline
\end{tabular}

Table 10

The result of forecasting performance of ARIMA-GARCH modelling

\begin{tabular}{lcccccl}
\hline \multirow{2}{*}{ Location } & Station & \multicolumn{2}{c}{ ARIMA } & \multicolumn{2}{c}{ ARIMA-GARCH } & Forecasting \\
\cline { 3 - 6 } & & RMSE & MAPE & RMSE & MAPE & Interpretation \\
\hline $\begin{array}{l}\text { Lubok } \\
\text { Merbau }\end{array}$ & NS5 & 1.4401 & 15.4814 & 1.4529 & 15.6325 & Good \\
Subang & CS11 & 1.7758 & 17.3518 & 1.7697 & 16.6947 & Good \\
Senai & SS18 & 1.9686 & 17.7601 & 2.0671 & 17.6552 & Good \\
\hline
\end{tabular}

Based on these results, it shows that even though the ARIMA model has proven to be adequate in modelling these 3 stations, the ARIMA-GARCH modelling also gives a good forecasting accuracy based on the forecasting interpretation by Lewis (1982). These models can be used in forecasting the daily wind speed in the wind station with a good forecasting result.

\section{CONCLUSION AND FUTURE WORK}

This study led to the construction of a time series model of daily wind speed series of 18 meteorological stations in Peninsular Malaysia. The Box-Jenkins ARIMA modelling was 
used to build a model of wind speed series for each station. In measuring the adequacy of the proposed ARIMA model, 3 stations: NS5, CS11, and SS18, were proven to be suitable for forecasting the wind speed series using the ARIMA model while the 15 other stations are affected by the presence of serial autocorrelation as well as ARCH effects. To overcome the issue, we used the ARIMA-GARCH model for 15 stations. The results show that 10 stations were successfully modelled using the ARIMA-GARCH model while 5 stations required other methods of modelling. Future work is needed to improve the limitation of the ARIMA-GARCH model for the remaining 5 stations. As for the 13 stations that had successfully been modelled using the time series, future work can be done by calculating the wind power density of each stations in Peninsular Malaysia in order to provide a quantitative measure of wind energy available in the potential location for renewable energy conversion.

\section{ACKNOWLEDGEMENT}

The authors would like to acknowledge Universiti Teknikal Malaysia Melaka, Universiti Teknologi Malaysia, and those who gave support in carrying out this research under the grant vote number Q.J130000.2654.17J30.

\section{REFERENCES}

Ajayi, O. O., Ohijeagbon, O. D., Nwadialo, C. E., \& Olasope, O. (2014). New model to estimate daily global solar radiation over Nigeria. Sustainable Energy Technologies and Assessments, 5, 28-36. doi: https:// doi.org/10.1016/j.seta.2013.11.001

Akcan, S. (2017). Wind speed forecasting using time series analysis methods. Çukurova University Journal of the Faculty of Engineering and Architecture, 32(2), 161-172.

Barbosa de Alencar, D., de Mattos Affonso, C., Limão de Oliveira, R. C., Moya Rodriguez, J. L., Leite, J. C., \& Reston Filho, J. C. (2017). Different models for forecasting wind power generation: Case study. Energies, 10(12), 1-27. doi: https://doi.org/10.3390/en10121976

Bollerslev, T. (1986). Generalized autoregressive conditional heteroskedasticity. Journal of Econometrics, 31(3), 307-327.

Chang, G. W., Lu, H. J., Hsu, L. Y., \& Chen, Y. Y. (2016, July 17-21). A hybrid model for forecasting wind speed and wind power generation. In 2016 IEEE Power and Energy Society General Meeting (PESGM) (pp. 1-5). Boston, MA, USA. doi: 10.1109/PESGM.2016.7742039

De Freitas, N. C., Silva, M. P. D. S., \& Sakamoto, M. S. (2018). Wind Speed Forecasting: A Review. International Journal of Engineering Research and Application, 8(1), 4-9. doi: 10.9790/9622-0801010409

Engle, R. (2001). GARCH 101: The use of ARCH/GARCH models in applied econometrics. Journal of Economic Perspectives, 15(4), 157-168. doi: 10.1257/jep.15.4.157 
Engle, R. F. (1982). Autoregressive conditional heteroscedasticity with estimates of the variance of United Kingdom inflation. Econometrica: Journal of the Econometric Society, 50(4), 987-1007. doi: https://doi. org/10.2307/1912773

Erdem, E., Shi, J., \& She, Y. (2014). Comparison of Two ARMA-GARCH Approaches for Forecasting the Mean and Volatility of Wind Speed. In International Congress on Energy Efficiency and Energy Related Materials (ENEFM2013) (pp. 65-73). Cham, Switzerland: Springer. doi: https://doi.org/10.1007/978-3319-05521-3_9

Grigonytė, E., \& Butkevičiūtè, E. (2016). Short-term wind speed forecasting using ARIMA model. Energetika, 62(1-2), 45-55. doi: https://doi.org/10.6001/energetika.v62i1-2.3313

Jamaludin, A. R., Yusof, F., Kane, I. L., \& Norrulasikin, S. M. (2016, June). A comparative study between conventional ARMA and Fourier ARMA in modeling and forecasting wind speed data. In AIP Conference Proceedings (Vol. 1750, No. 1, p. 060022). New York, USA: AIP Publishing LLC. doi: https://doi. org/10.1063/1.4954627

Kim, E., Ha, J., Jeon, Y., \& Lee, S. (2004). Ljung-Box test in unit root AR-ARCH model. Communications for Statistical Applications and Methods, 11(2), 323-327.

Kwiatkowski, D., Phillips, P. C., Schmidt, P., \& Shin, Y. (1992). Testing the null hypothesis of stationarity against the alternative of a unit root. Journal of Econometrics, 54(1-3), 159-178.

Lewis, C. D. (1982). Industrial and business forecasting methods: A practical guide to exponential smoothing and curve fitting. Penang, Malaysia: Heinemann Publisher.

Lojowska, A., Kurowicka, D., Papaefthymiou, G., \& van der Sluis, L. (2010, June 14-17). Advantages of ARMAGARCH wind speed time series modeling. In 2010 IEEE 11th International Conference on Probabilistic Methods Applied to Power Systems (pp. 83-88). Singapore. doi: 10.1109/PMAPS.2010.5528979

Lujano-Rojas, J. M., Bernal-Agustín, J. L., Dufo-López, R., \& Domínguez-Navarro, J. A. (2011). Forecast of hourly average wind speed using ARMA model with discrete probability transformation. In M. Zhu (Ed.), Electrical Engineering and Control (pp. 1003-1010). Heidelberg, Germany: Springer. doi: https:// doi.org/10.1007/978-3-642-21765-4_125

Masseran, N. (2016). Modeling the fluctuations of wind speed data by considering their mean and volatility effects. Renewable and Sustainable Energy Reviews, 54, 777-784. doi: https://doi.org/10.1016/j. rser.2015.10.071

Miswan, N. H., Said, R. M., Hussin, N. H., Hamzah, K., \& Ahmad, E. Z. (2015). Comparative performance of ARIMA and DES models in forecasting electricity load demand in Malaysia. International Journal of Electrical and Computer Sciences IJECS-IJENS, 16(1), 6-9.

Moreno, J. J. M., Pol, A. P., Abad, A. S., \& Blasco, B. C. (2013). Using the R-MAPE index as a resistant measure of forecast accuracy. Psicothema, 25(4), 500-506.

Norrulashikin, S. M., Yusof, F., \& Kane, I. L. (2018). Meteorological multivariable approximation and prediction with classical VAR-DCC approach. Sains Malaysiana, 47(2), 409-417.

Petinrin, J. O., \& Shaaban, M. (2015). Renewable energy for continuous energy sustainability in Malaysia. Renewable and Sustainable Energy Reviews, 50, 967-981. doi: https://doi.org/10.1016/j.rser.2015.04.146 
Radziukynas, V., \& Klementavicius, A. (2014, October 14). Short-term wind speed forecasting with ARIMA model. In 2014 55th International Scientific Conference on Power and Electrical Engineering of Riga Technical University (RTUCON) (pp. 145-149). Riga, Latvia. doi: 10.1109/RTUCON.2014.6998223

Sharma, R., \& Singh, D. (2018). A review of wind power and wind speed forecasting. Journal of Engineering Research and Application, 8(7), 1-9. doi: 10.9790/9622-0807030109

Sharma, S. K., \& Ghosh, S. (2016). Short-term wind speed forecasting: Application of linear and non-linear time series models. International Journal of Green Energy, 13(14), 1490-1500. doi: https://doi.org/10.1 080/15435075.2016.1212200

Sjölander, P. (2011). A stationary unbiased finite sample ARCH-LM test procedure. Applied Economics, 43(8), 1019-1033. doi: https://doi.org/10.1080/00036840802600046

Wang, J., Hu, J., Ma, K., \& Zhang, Y. (2015). A self-adaptive hybrid approach for wind speed forecasting. Renewable Energy, 78, 374-385. doi: https://doi.org/10.1016/j.renene.2014.12.074

Wang, W., Van Gelder, P. H. A. J. M., Vrijling, J. K., \& Ma, J. (2005). Testing and modelling autoregressive conditional heteroskedasticity of streamflow processes. Nonlinear Processes in Geophysics, 12(1), 55-66.

Yan, J., Guoqing, H., Xinyan, P., \& Yongle, L. (2016). Method of short-term wind speed forecasting based on generalized autoregressive conditional heteroscedasticity model. Journal of Southwest Jiaotong University, 51(4), 663-669.

Yaziz, S. R., Azizan, N. A., Zakaria, R., \& Ahmad, M. H. (2013, December 1-6). The performance of hybrid ARIMA-GARCH modeling in forecasting gold price. In 20th International Congress on Modelling and Simulation (pp. 1201-1207). Adelaide, Australia.

Yürekli, K., Kurunç, A., \& Öztürk, F. (2005). Testing the residuals of an ARIMA model on the Cekerek Stream Watershed in Turkey. Turkish Journal of Engineering and Environmental Sciences, 29(2), 61-74.

Yusof, F., Kane, I. L., \& Yusop, Z. (2013). Hybrid of ARIMA-GARCH modeling in rainfall time series. Jurnal Teknologi, 63(2), 27-34. 